\title{
Know My Language, Know My Music, Know My Culture: Adapting a music education unit in regional Australia to meet the individual needs of pre-service teachers
}

Sharon Melinda Lierse*

Charles Darwin University sharonlierse.academicme@gmail.com 


\begin{abstract}
Music is an integral part of society. How it is taught and represented in educational institutions reflects the educational values. Moreover, it is part of a nation's cultural fabric. The paper will discuss the issues pertaining to music education courses in Australia and postulate why an individualised curriculum for secondary music teachers at the pre-service teacher stage is necessary. From this, an existing unit has been adapted for online learning to meet the needs of pre-service teachers in regional and remote areas of Australia. A mix methods approach of Critical Discourse Analysis and Participation Action Approach has been used. This has been necessary to identify and understand the issues of identity, access and inclusiveness in a multicultural society. Through these changes, the unit was transformed to better align with the individual needs of pre-service teachers, online learning, the changing environment of schools, and the Year 11 and 12 music curricula.
\end{abstract}

Keywords: Australian Curriculum, equity, Indigenous music, music education, online learning 


\section{Introduction}

Music is an integral part of society. How it is taught and represented in educational institutions reflects the educational values. Moreover, it is part of a nation's cultural fabric. Australia is a relatively young country and was colonised by the British in the eighteenth century. Due to Australia's geographic isolation and large distances between cities, there are challenges in travel and communication. Geoffrey Blainey, an Australian academic historically coined this the "tyranny of distance" where he recognised this barrier as a key factor in its uncertainty in its economic future and cultural identity (BLAINEY, 1966). Australia is also a country of migrants in which there are over 150 languages and cultures represented. This poses issues of understanding what it means to be an Australian, and how Australian culture is manifested in society.

Although Australia is regarded as a young country, it has a long and rich Indigenous history. There are over 100 recognised Aboriginal and Torres Strait Islander groups each with their own languages, traditions and cultures. The Northern Territory is a region of Australia unique for its large geographic area, high Indigenous population and sparsely populated communities. Due to these factors, some schools in the area are difficult to access and may have students whose first language is not English. For a population of around 240,000, the Northern Territory has the highest percentage of Aboriginal and Torres Strait Islanders in Australia comprising approximately forty per cent of the population (MISON, 2015, p.10). There have been ongoing issues with equity and accessibility especially for students in regional and remote areas. There is also an overriding issue of identity and belonging. This is often expressed through the types of music learnt and played in local communities and educational institutions. What music is accepted can also reflect which cultures are dominant in society.

Which styles of music are learnt in schools makes a lasting impact on the person in terms of their own identity and place in society. In the case of music in Australian schools, especially in regional and remote areas, a "one syllabus fits all" approach is not going to work. To only use music from the traditional Conservatoire model will deny music and its meaning from other communities. It is the universities which have much influence and responsibility for what is taught in schools. The teacher training courses for music educators have a far greater impact beyond learning about curricula. They indirectly teach which styles of music are valued, honoured and accepted in society. In doing so, there is also the risk of disregarding other styles of music including popular, folk and Indigenous music. The paper will discuss the issues pertaining to music education courses in Australia and postulate why an individualised curriculum at the pre-service teacher stage is necessary. From this, an existing unit has been adapted in an online format to meet the needs of pre-service teachers including those in regional and remote areas of Australia. 


\section{Literature Review}

There is an understanding that "music exists in every human culture on earth" (GOLDEN, 2011, p.31). The function and meaning of music does vary across cultures including relationships between people and social groups. Drummond (2010) commented how "For many of us, music is central to our sense of who we are" (p.118). Argstatter (2016) compared six emotions communicated across cultural boundaries in Western Europe and Asia. It was found that the level of musical training did impact the results. There was also a cultural advantage known as "in-group advantage" for those people from the same culture (p.685).

Music training in institutions is determined by what is assessed in which perpetuates what is deemed important (BIGGS \& TANG, 2011; SMALL, 1977). This includes what type of music is taught in a pre-service music education unit. According to Small (1977) in tertiary music institutions "one greatly regrets that only a tiny, arbitrarily chosen, sector is accessible to any individual student; the rest, if he is aware at all of its existence, is put out of his reach by the demands of the syllabus and the examinations" (p.187). Cain (2005) points out "for many music teachers, however, their educational goals and learning outcomes have been filtered as a result of life experiences, and thus unintentionally coloured by prejudices, stereotypes, and sometimes misconceptions" (p.104). Introducing Indigenous music to a course has been discussed from the viewpoint of Native American music. Burton and Dunbar-Hall (2002) commented how, "Acceptance of these musics, and clarity about the implications of the study of them, is however only the initial step in the ongoing development of music education as an equitable enterprise" (p.62). Lee (2018) researched how it is the background of the teachers which impact what music are taught in schools: "The findings also revealed that the teachers' ethnic backgrounds might affect their repertoire selection, because of familiarity" (p.41). Music education can be approached through an ethnomusicological approach (VOLK 2004). Howard, Swanson and Shehan Campbell (2014) discussed different approaches to diversifying music education in American schools through a series of vignettes. Cain (2005) pointed out, "Despite the multicultural make-up of Australia, the music education of many students has been, and currently is, predominantly Eurocentric in nature" (p.104). Bowen (2011) discussed how "the rich cultural legacy of the traditional owners of the land has been slow to be acknowledged as enhancing cultural life not only for Indigenous but for all Australians" (p.102).

Universities have undergone a transformation in the twenty-first century to a student -centred approach (BIGGS, 2001; HUNT \& CHALMERS, 2012). Online learning has become more popular during the past decades but is also complex (REEVES \& REEVES, 2012). Online courses also have enabled students who otherwise could not attend, access and opportunity for higher education. Music education as a subject has also embraced technology (BAKER, 2012; BAKER, 2013; SALAVUO, 2006). Music education has constantly been under threat due to its relative low status, quality of teaching, crowded curriculum and low numbers of students (COMMONWEALTH OF AUSTRALIA, 2005). 


\section{Methodology}

The study will use a mix methods qualitative approach. This has been required to first identify and understand why only particular types of music have been recognised and promoted in an Australian educational context, deconstruct these issues, and create an alternative pathway. In order to understand the issues, a Critical Discourse Analysis approach has been used. This is based on Critical Pedagogy. In Freire's Pedagogy of the Oppressed education is used to perpetuate privilege and social control through isolating and not providing a voice for those who are not in the dominant groups: "They want to save their riches, their power, their way of life: the things that enable them to subjugate others" (1970, p. 146). In music education, a music educator has the power and responsibility to provide a voice for pre-service teachers who can offer all styles of music. Critical Discourse Analysis is "fundamentally concerned with analysing opaque as well as transparent structural relationships of dominance, discrimination, power and control as manifested in language" (WODAK, 2000, p. 2). Here, a university course may not accommodate those who are not from a dominant paradigm despite their initial acceptance into tertiary study. Through analysing how inequality has been manifested through language in existing course requirements, it is then possible to redress issues of inequity through traditionally accepted styles of music learnt and taught in a university setting.

Participation Action Research (PAR) is used as the method to inclusively adapt an existing unit of work to meet the needs and requirements of the pre-service teachers, lecturers and the university. The process was selected as it involved input from the unit, lecturer and the pre-service teachers. In this situation, the unit was designed according to the requirements by the university in which there was scope for changing the content and assessment tasks. The lecturer had experience in teaching similar units in the course and could use this knowledge for transforming the unit. The cohort of students was small usually comprising fewer than five students, so student data was from phone and email discussions. If the cohort was large, a different approach would have been used.

The four steps in Participation Action Research are: planning a change; acting and observing the processes and consequences of change; reflecting on the processes and consequences; and replanning to start the cycle again (KEMMIS \& MCTAGGART, 2005, p. 595). Planning a change was required for adapting the unit for a more individualised approach. Stage two "acting and observing the processes and consequences of change" involved the adaptation of the existing unit to enable students from different musical backgrounds to engage in the unit. The third stage "reflecting on the processes and consequences" gave the lecturer time to review how the unit had changed and its efficacy. "Replanning to start the cycle again" was the final stage which would occur prior to a new semester. Through understanding the issues and associated impact of why some styles of music are accepted in education contexts, the lecturer can adjust the music education unit to suit the individual needs of the students. In this study, the cycle occurred twice, initially when teaching the unit for the first time and secondly after the changes had been made. During the semester, the lecturer would ask feedback from the students and check unit requirements before making changes for the following semester. 


\section{Education in Australia}

The school system in Australia was largely founded on the British system of public schools, church schools and government schools (CAMERON, 1969). Students attend school which has been compulsory for students from the age of five to fifteen. Following on they complete their High School Certificate set by each respective State and Territory which takes an additional two years. There is a great variety between schools and school systems in Australia depending on its geographic location, cultural background of its students, and access to funding.

The Australian Curriculum and Assessment Reporting Authority known as "ACARA" has developed an Australian Curriculum for students from Foundation up to Year 10 of schooling. In 2011, the Australian Curriculum was introduced in Australian schools (AUSTRALIAN CURRICULUM, AND REPORTING AUTHORITY, 2016). Schools are encouraged to use the Australian Curriculum but have the liberty to develop their own syllabus to reflect the individual school's culture. Some schools, however still use their existing State and Territory based curricula where this resistance may stem from a loss of local cultural identity.

The arts are compulsory in the Australian Curriculum in which music is one of the five subjects together with visual art, media art, dance and drama. Music is a subject offered in Australian primary and secondary schools. Although teaching all the five arts are not compulsory, the inclusion of at least one arts subject is mandated in the Australian Curriculum (AUSTRALIAN CURRICULUM, AND REPORTING AUTHORITY, 2016). The music subjects taught in Australian schools are usually divided into classroom music and instrumental music. Classroom music is taught to students in a generalist class and is part of the school curriculum. The subject areas comprise music history, composition, theory, aural training or performance. Instrumental music is often an elective subject and its delivery varies between schools (Lierse, 2005). Because music is not a compulsory or mandated subject in the curriculum, some schools do not offer music in favour of the other arts. Consequently, some students may not experience music education during their compulsory ten years of schooling.

In Years 11 and 12, each State and Territory has their own curriculum in which Music is one of the elective subjects. Traditionally a performance-oriented subject, students are now required to complete written work such as analysis, theory, aural training and composition. A major change has been the introduction of popular music, and group music. Music educators who teach Year 11 and 12 Music are expected to offer a range of skills at the standard for school students to have the option of applying to a music performance course at a university. Due to the small number of students in music elective subjects and its relatively low status, there is pressure for the music teacher at schools, especially in the high levels to be of the highest quality.

The issue of access and equity of music programs in Australian schools was investigated in 2005 with a government review. Entitled the National Review into School Music Education: Augmenting the diminished, the investigation provided a snapshot of music programs in schools. (COMMONWEALTH OF AUSTRALIA, 2005) There were 
pockets of excellence but there was inconsistency in the provision and quality of music programs. The research found that 9.4 per cent of sample schools did not have a music program in which the review committee calculated from the results that conservatively 900 schools may not have a music program at all (p.64). This was perceived as a crisis in music education and solution was to "increase the attention placed on the quality of music programmes and the place of music in the curriculum" (LIERSE, 2006).

The issue of access, equity and quality of music education in Australian schools has not drastically improved since the National Review of School Music Education in 2005. This ranged from the low number of music programs, lack of preparation of pre-service teachers (GARVIS \& LEMON, 2013, p.101) to the lack of change in the decade following the Review. This has also been the case in the Northern Territory which has the added dimension of geographic isolation compared to other capital cities.

Another influence on the Australian school system has been the Melbourne Declaration on Educational Goals for Young Australians. This was jointly published by Australian Education Ministers in 2008. In the preamble, it stated:

As a nation Australia values the central role of education in building a democratic, equitable and just society - a society that is prosperous, cohesive and culturally diverse, and that values Australia's Indigenous cultures as a key part of the nation's history, present and future (MINISTERIAL COUNCIL OF EDUCATION, EMPLOYMENT, TRAINING AND AND YOUTH AFFAIRS, 2008, p.4).

This exemplified that at a policy level, diversity was to be embraced and accepted. A goal was for students to become "creative individuals and active and informed citizens". This could be achieved through the acceptance of different types of music offered at schools.

\section{Education in Northern Territory Schools}

The Australian Curriculum was implemented in the Northern Territory in which all five art forms including music were included. The Northern Territory had a role in the development of the curriculum in which they identified Indigenous students and engagement with Asia as a cross-curriculum priority. The existing Northern Territory Curriculum Framework (NTCF) is still in use at some schools and provides a curriculum from Transition to Year 9 (NORTHERN TERRITORY BOARD OF STUDIES, 2013). Here, the arts are also mandated in the curriculum although music is not a compulsory subject.

The National Aboriginal and Torres Strait Islander Education Strategy (AUSTRALIAN GOVERNMENT DEPARTMENT OF EDUCATION AND TRAINING, 2015) was created with an aim to "accelerate the rate of improvement for Aboriginal and Torres Strait Islander student outcomes". The arts are central in Indigenous life and culture and is a pathway for a meaningful and relevant education. The areas for improvement included; attendance and engagement, transition, workforce and Australian Curriculum. The late Mandawuy Yunupingu, leader of the band of Yothu Yindi and Principal of Yirrkala school stated how "Song is imbedded in the Aboriginal psyche and worldview" (YUNUPINGU, 2009). 
Andy Mison, who was the Principal of the Northern Territory Music School wrote a report in 2015 on the state of arts education programs in government schools in the Northern Territory. It was entitled: "How Can Northern Territory Government Schools Implement a Quality Arts Education Program for Every Student?" In the report, he examined the issues regarding educational policy and equity arts programs in the Northern Territory. The themes arisen were equity, access and acknowledging Indigenous communities in and through the arts. According to the survey results, there were issues with access and equity to arts programs - the biggest inhibiting factor being funding and the lack of availability to professional learning. The study found that the biggest enabling factor were teachers' positive disposition towards the arts (MISON, 2015, p. 20). What this revealed was that schools wanted an arts program with music being the most popular, but there were barriers to funding, access and equity across the Northern Territory. His specialisation in music education was a focus area in the report. With the unique geographic location of the Northern Territory, he found that the provision:

has long been marginalised by inhibiting factors such as the higher quality given in curriculum and resourcing in other areas, a shortage of specialised capacity among teachers, insufficient appropriate professional learning opportunities, and no co-ordinated strategy to deliver evidence based and effective services as an education system (MISON, 2015, p.3).

It is the training of pre-service secondary music teachers which is the focus. Many of these students reside in the regional or remote areas of Australia. They hadn't been provided with access to be exposed to Western Classical music, nor learnt through a one-to-one master and apprentice model. Music to them was defined through their peers, communities and generations of Songlines.

\section{Why Music Education Courses Should Be Individualised}

Pre-service teachers are required to complete a series of units to prepare them for the profession. In the course, there are compulsory core units which may include - child development, philosophy and psychology of education, curriculum design and teaching placements. These core education units are often designed as a "one size fits all" format. This is to ensure that the required information is covered, and to create a manageable workload for the lecturers. The content is fixed, and the assessment tasks are perceived as approachable and relevant for all students.

Pre-service teachers who want to work in secondary schools comprising students aged 12 to 18 usually require two subject specialisations. Music education can be one of these. subjects. Subject specialisations pose a different set of challenges. Lecturers in subjects such as literacy, numeracy and science generally have a more homogenous curriculum and the subjects are compulsory for all students for a significant part of their schooling.

In secondary education, the subject "music" may be compulsory in the first one or two years of secondary schooling, but then is an elective for the final four years of sec- 
ondary education. An issue with classroom music is that it attracts small numbers of students in the elective units and it is up to the strength and enthusiasm of music teachers to promote the subject. There is a wide range of styles, instrument types and specialisations which makes teaching this subject complex. This variety presents challenges to the educator and the student. One would expect that in music there would be a common language, but unfortunately this is not the case. Communicating through a music language such as using the stave developed in the European Western tradition cannot be assumed. For instance, some guitar students use tablature, vocalists have learnt by ear and some Aboriginal and Torres Strait Islander students use Songlines passed through the generations. A generic "one fits all" course would not work for pre-service teachers whose skills, strengths, and cultural backgrounds were vastly different. Additionally, the unit is offered online due to advances in technology and to for students who reside in regional and remote areas. This poses another set of challenges.

\section{Secondary Music Unit for Pre-Service Teachers}

The two units offered for pre-service teachers are Teaching the Curriculum: Music 1 and Teaching the Curriculum: Music 2. They are required to be taken as a sequence, first with Music 1 which is teaching Music from Years 7 to 10 then Music 2 which are for students in Years 11 to 12. Teaching the Curriculum: Music 2 is the focus as it highlights the diverse and advanced skill sets of pre-service teachers, and why the unit needed to be individualised.

The unit Teaching the Curriculum: Music 2 runs for twelve weeks during the semester and is only offered online. A full-time student would study four units during the semester and the recommendation is 10 hours of study per week. Work is presented as a series of online modules which is set by the lecturer and the student works through at their own pace. It is up to the lecturer how the information is presented. This could be text, blogs, PowerPoint presentations, Discussion Board, online discussion, links to websites and YouTube clips. Students may or may not have interaction with other members of the class. There is a university requirement for the lecturer to include strategies to teach Indigenous students as well as students with diversity such as those with special needs. Online learning enables students from a wide range of backgrounds to have the opportunity to learn, provided they have computer access, and with the rapid advantages in technology students have access to a wide range of resources.

It is up to the lecturer to set assessment tasks and the norm has been for two major assessment tasks submitted online: one at the middle and the other at the end of the semester. The student is marked out of 100 and the pass mark is 50 . Therefore, full-time students usually have all their assessment tasks at the middle and end of semester.

There are advantages in learning online, but there are also issues in equity, accessibility and community building when engaging in music. Music education is fundamentally a hands-on experience where face-to-face engagement with other students is the optimal way to learn. They reside in different states or territories and use different curricula. When students live remotely, they do not have the opportunity to establish 
connections where they can practise music in a group with others. Challenges such as finding mutual times for a collaborate session make activities such as community singing, or instrumental ensembles next to impossible. Students may be from multicultural backgrounds and if they needed to upgrade skills, is difficult to accomplish. The diversity in such a small class, usually fewer than five enrolled each semester also presents issues of finding common ground.

\section{Planning a Change}

The music education lecturer was a cellist trained at a Conservatoire of music in an Australian major capital city. This was not a match with the specialisation of students which ranged from: an Indigenous popular music vocalist living in Darwin; a jazz singer in the German township in South Australia; a pop guitarist in the whose own music tuition was via YouTube, and a jazz and big band trumpeter from Adelaide. It was apparent that the traditionally dominant Classical Western music tradition was outdated for the pre-service teachers and a change was required if the unit was going to be successful. The majority of students who learn music are not being trained to work as Classical Orchestral musicians. The Conservatoire model was irrelevant for this cohort of pre-service teachers. Therefore, a new approach was required.

The lecturer was presented with the unit outline for Teaching the Curriculum: Music 2 a week before semester commenced. At that stage it was too late to make any changes. There were fewer than five students enrolled which enabled to lecturer to make personal contact with each student via phone or Skype. There was a mismatch between the university unit curriculum, school syllabus, background of the lecturer, and the skill sets of the students. These would have to be better aligned for a more successful student experience.

The university curriculum was skewed to students who were familiar with twenty-first century learning. The first module was "Political, Social, Technological and Economic Factors" in twenty-first century learning. However, this was not music focused and for those styles of music which required face-to-face engagement was not relevant. At this stage, the lecturer was questioning the utility of the module in a music unit. The second module "Expressiveness in Performance" was designed for students to explore emotion in their playing. For a music education subject, the module was vague and difficult to measure. The third module was a series of five lesson plans to match the South Australian Certificate of Education. There were students from other States and Territories in Australia which use a different school curriculum. The final module was a twenty-minute solo or group recital to match the syllabus requirements of South Australia. The solo performance works were from the expected Classical orchestral instruments as well as group popular music. There was a rapid growth in group rock and popular music in the Year 12 music syllabi in Australian States and Territories. However, there was still a bias and expectation from universities and schools for music students to follow the traditional Conservatoire model. 
The assessment tasks were in Week 10 and 12 which was late in the semester. If university students were unclear whether to withdraw before Census Date which was usually in Week 5, they did not have sufficient opportunity for feedback from the work. The curriculum was also designed for students to work in isolation without input form their peers.

Table 1. Original assessment tasks

\begin{tabular}{l|l|l}
\hline Assessment Task & Percent of total mark & Due Date \\
\hline Five lesson plans & 50 per cent & Week 10 \\
\hline $\begin{array}{l}\text { Solo performance with } \\
\text { reflection of } 750 \text { to } 1,000 \\
\text { words }\end{array}$ & 50 per cent & Week 12 \\
\hline
\end{tabular}

During the semester, the lecturer asked for feedback on the content and assessment tasks. After the semester, the lecturer reviewed the unit to update the content and assessment tasks. Suggestions were from the students who wanted to be music educators but felt disengaged from the experience. There was also a sense of isolation from studying online and alone as well as their musical skills not being acknowledged.

\section{Acting and Observing the Processes and Consequences of Change}

The challenge in the unit was to make the learning tasks generalised enough to make them relevant to all pre-service teachers yet maintain the required university standard and interest of the students. There was an issue of attrition in courses for a variety of reasons, and some students took several years to complete the course due to dropping to part-time study due to work and family issues.

One trend in Australian school music education has been the rapid growth in popular and group music in which this is now a recognised subject in the final year music performance curriculum in the respective States and Territories. At the university level, there was still the issue of the acquisition of music education skills such as theory, aural training, history and styles in which all students came into the unit with a different knowledge point.

The major change was to transform the thinking behind the unit from the same format to any other undergraduate course to individualised mini-supervision sessions for students who may one day be studying a Masters by research. With a relatively small cohort, individualised teaching was possible. Moreover, this new style kept the student engaged with the unit and more positive about what they could bring into their own music education. The structure of these phone or Skype sessions was to work backwards from the final goal. The phone or Skype conversation usually occurred the week before the beginning of the semester, or during the first week.

Questions asked in the first session were:

1. Where do you see yourself teaching music?

2. Have you been on a music teaching placement, and if so what did you teach? 
3. What secondary music programs do they currently have in the city or town?

4. Do they have a year 12 music class, and if so what do they teach?

5. What skills can you bring into the program?

6. Do you have other related skills you can bring into a music program? Such as dance?

7. What curriculum or syllabus do they use?

8. What skills do you need to further develop?

9. What curriculum documents do you need to use?

10. What do we need to include in a plan to achieve this?

From the conversation, each student was provided with the task of following up any of these questions which were not clarified during the conversation. They were also asked to look at the assessment tasks for the units. It was at this early stage that some of the students from the small cohort decided not to continue. The reasons given was the workload, work-life balance, expectations of teaching Year 11 and 12, and requiring more time to upskill before commencing the semester. The existing online modules were left as a reference in case they required background information or discuss ideas with the other students.

During the semester, all students received a weekly announcement sent on Monday. This would include updates to the unit, course and university changes. This made the students feel more part of the institution.

A major change was the introduction of a hurdle task in Week 3 where they submitted their recital program for discussion and approval. The purpose of the recital was to prepare and experience a Year 12 recital which was the same requirement for students in Year 12. To date, the pre-service teachers had not completed Year 12 music in its current format, and the experiential approach would prepare them for the task of teaching students in the future.

The five lesson plans were adjusted to be aligned with a specific module of work from a Year 11 or 12 Curriculum in their respective State or Territory. There was an accompanying set of prescriptive notes added to the existing assessment task to guide the student:

Accompanying Notes: Plan a series of five (5) lessons for senior music students (Years 11 \& 12) using lesson framework or structures relevant to music and demonstrate the capacity to organise classroom activities through clear directions and scaffolding.

The focus of the lessons should be on providing opportunities for students to utilise music as a valuable problem solving, creative and expressive thinking medium and awareness that music is instrumental in the development of artistic, aesthetic and creative skills, attitudes and values

Before you begin the task, you need to consider the following:

1. Which year level will you choose to plan your lessons for?

2. How long is a lesson? (this may require some research as to what is the usual time for a lesson at the senior level) 


\section{What is the topic?}

4. Where do the lessons fit in the topic?

5. What resources will you need for the lessons?

6. How are the lessons distributed on the timetable (are they single or double lessons)?

7. Are the lessons theoretical or practical or both?

8. What are the skill levels of the students?

9. Do the students have any previous experience of the topic you are teaching?

10. How will you know if the students have gained an understanding of what you have been teaching them?

These ten questions provided scope for further discussion between the lecturer, peers and student. For many of these students, this was the first time they had engaged with a senior curriculum and planned work at this level.

The final assessment task was the Solo or Group performance submitted via YouTube or equivalent with accompanying notes on the background of the works and a reflection on the process. This task required them to play at the required practical level for a Year 12 student, research into the background of the works, and a personal reflection of the journey.

The major changes were; the initial conversations to gauge what their starting point in the unit, how the unit could be tailored for their unique situation, weekly updates, Week 3 submission of the recital program, and the changes to the assessment tasks. These catered for a more individualised approach and for students from multicultural backgrounds.

Table 2. Revised assessment tasks

\begin{tabular}{l|l|l}
\hline Assessment Task & Percent of total mark & Due Date \\
\hline Program recital plan & Hurdle requirement & Week 3 \\
\hline Five lesson plans & 50 per cent & Week 6 \\
\hline $\begin{array}{l}\text { Solo or group performance } \\
\text { with performance notes } \\
\text { and reflection of } 750 \text { to } \\
1,000 \text { words }\end{array}$ & & Week 12 \\
\hline
\end{tabular}

\section{Reflecting on the Processes and Consequences}

The changes to the more personalised teaching approach through contacting the students was first met with trepidation. This process was not seen as the norm and to other lecturers as a waste of time, especially if they had larger cohorts of students. There was also the issue of finding a mutual time to contact them, and with technology. This was experienced with international students who were residing overseas in which English was their second language. However, the feedback from the students after the assessment tasks was one of gratitude. I was the first lecturer that had not only had bothered to contact them, but also listened to who they were, what their needs were, 
and what they required from the unit, course and the university. Following on emails were less formal as the lecturer and student were familiar with each other. The relationship had changed from less of a lecturer student relationship to a mentor and mentee. During the semester, there were more follow up emails from the students, and they were not afraid to contact the lecturer earlier if they were experiencing difficulties in their progress.

The most significant change was that the students felt a sense of efficacy and worthiness in what they could offer as music educators. This was through validation that their musical skills had a place in the school curriculum. The point of difference of musical backgrounds was initially thought to be a barrier but was used to an advantage. Students could understand that they were not outliers and excluded from the academy but could offer something unique. This was mostly from performers in popular music in which that option was not available to study when they were school students.

The students found the earlier due dates easier to balance their work, and to decide whether they could commit to the unit. Often in the online environment, students take on too much believing they could handle the workload.

The change to more prescriptive assessment tasks yet providing them with scope for individualised learning worked to their individual strengths. Using an experiential approach where they completed the assessment tasks which their future students would encounter also helped the students understand what it would be like for their school students, and better prepare them in a learning and teaching situation.

\section{Re-planning to Start the Cycle Again}

The verbal feedback from the pre-service teachers and changes to the curricula around Australia helped to further modify the unit. One recent change in the school music curriculum has been a greater emphasis on composition. For the next semester, this will be reviewed as to how composition can be incorporated as a learning task without overloading the students with too many assessment tasks.

Through reviewing and modifying the unit each semester, the work has remained as up-to-date and relevant for students to address the issues of accessibility and equity, especially for those who otherwise would not have the opportunity to become teachers in remote and regional areas of Australia.

\section{Discussion}

The music education unit underwent a transformation in which the assessments were rewritten to accommodate a more individualised learning and teaching experience. The rationale for this change was due to the lecturer recognizing that perpetuating the existing dominant discourse would not work at a university with students from such diverse backgrounds. The traditional Conservatoire model did not exist in the university education course, nor in the initial training of the pre-service teachers, therefore 
a change was necessary. If there was a bigger cohort of students, or the majority from the Conservatoire tradition, this would have been different.

An issue with being inclusive for pre-service music teachers was standards and equitable marking in their assessments. There was a challenge in finding a balance between allowing all pre-service teachers who were interested in teaching music into the unit and maintaining a standard which would be acceptable at the university and as a teacher in a school environment. There has been criticism from some schools that music teachers should be fluent in reading music, demonstrate a high level of theoretical fluency, knowledge in history and perform at a high level of proficiency. If they did not fit into the mould, the university would be blamed for not adequately preparing the pre-service teacher. However, the other extreme of training pre-service teachers in the Conservatoire model has produced teachers who are "out of touch" with the needs of the students of today and their preferred styles of music. The lecturer had the challenge of knowing how to assess the students if one did not know the music, know the language, know the culture. Through these changes, the unit was transformed to better align with the individual needs of pre-service teachers, the changing environment of schools and the Year 11 and 12 music curriculum.

\section{Conclusion}

The music education unit was transformed for a more individualised approach for pre-service teachers. This was deemed necessary due to the backgrounds of the pre-service teacher, accessibility of music programs and the changing styles of music practiced in regional and remote areas in Australia. This change was possible due to the lecturer recognising that the traditional Conservatoire model may not be relevant, for all pre-service teachers, and other styles of music had their place in a university catering to students from diverse backgrounds. Music is an ever-evolving art form and adapting to these new styles and cultures would further enrich ones' experience of the world.

\section{References}

ARGSTATTER, H. Perception of basic emotions in music: Culture-specific ormulticultural? Psychology of Music, v.44, n.4, p.674-690, 2016.

AUSTRALIAN GOVERNMENT DEPARTMENT OF EDUCATION AND TRAINING. National Aboriginal and Torres Strait Islander Education Strategy. Retrieved from https://www. education.gov.au/national-aboriginal-and-torres-strait-islander-education-strategy, 2015.

AUSTRALIAN CURRICULUM, ASSESSMENT AND REPORTING AUTHORITY. The Arts. Retrieved from http://www.acara.edu.au/curriculum/learning-areas-subjects/the-arts, 2016. 
BAKER, W. J. Fully online learning in a pre-service teacher music education unit in Australia: Student perspectives. In W. Sims (Ed.), Proceedings of the International Society for Music Education 30th World Conference on Music Education Thessaloniki, Greece, p. 45-51, 2012.

BAKER, W. J. Student use of demonstration videos as learning tools in fully online arts education. In J. Wright (Ed.). Regional and global cooperation in educational research. Proceedings of the Australian Association for Research in Education National Conference. Sydney, NSW, 2013.

BIGGS, J. The reflective institution: Assuring and enhancing the quality of teaching and learning. Higher Education, v.41, n.3, p. 221-238. doi: 10.1023/A:1004181331049, 2001.

BIGGS, J. B.; TANG, C. Teaching for Quality Learning at University. Buckingham, UK: Open University Press, 2011.

BLAINEY, G. The Tyranny of Distance: How distance shaped Australia's history. Australia: Pan MacMillan, 1966.

BOWEN, E. Voices from the Living Heart: Healing Australia's dark past. In Laurence, F and Urbain (Eds). Music and Solidarity: Peace and Policy, New Brunswick: Transaction Publishers, v. 15, p.101-16, 2011.

BURTON, B.; DUNBAR-HALL, P. Teaching About and Through Native American Musics: An Excursion into the Cultural Politics of Music Education. Research Studies in Music Education, v.19, 56-64, 2002.

CAIN, M. Dabbling or deepening - Where to begin? Global Music in International School Elementary Education. In P. S. Campbell, J. Drummond, P. Dunbar-Hall, K. Howard, H. Schippers, \& T. Wiggins (Eds.), Cultural diversity in music education: Directions and challenges for the 21st century Brisbane: QCRC, p.103-112, 2005.

CAMERON, A.E. The Class Teaching of Music in Secondary Schools in Victoria 19051955: An investigation into the major influences affecting the development of music as a class syllabus in Victorian Secondary Schools. Unpublished Masters Thesis, The University of Melbourne: Melbourne, 1969.

COMMONWEALTH OF AUSTRALIA. National Review of Music Education: Augmenting the diminished. Canberra: Department of Education, Science and Training, 2005.

DRUMMOND, J. Re-thinking Western art music: A perspective shift for music educators. International Journal of Music Education, v.28, p.117-126, 2010. 
FREIRE, P. Pedagogy of the Oppressed. New York: Continuum, 1970.

GARVIS, S.; LEMON, N. Are the Arts important in schooling?: Clear messages from the voices of pre-service generalist teachers in Australia. Australian Journal of Music Education, v.2, p.98-104, 2013.

GOLDEN, M. "On Music, Interconnection, and Consciousness" In Laurence, F and Urbain (Eds). Music and Solidarity: Peace and Policy, New Brunswick: Transaction Publishers, p.31-46, 2011.

HOWARD, K.; SWANSON, M.; SHEHAN CAMPBELL, P. The Diversification of Music Teacher Education: Six Vignettes from a Movement in Progress. Journal of Music Teacher Education, v.24, n.1, p.26-37, 2014.

HUNT, L.; CHALMERS, D. University Teaching in Focus: A learning centred approach. Camberwell, Australia: Australian Council for Educational Research, 2012.

KEMMIS, S.; MCTAGGART, R. (2005). Participatory Action Research. In Denzin, N.K. Lincoln, Y.S. (Eds). The Sage Handbook of Qualitative Research. Thousand Oaks: Sage, 2005.

LEE, S. General Music Teachers' Backgrounds and Multicultural Repertoire Selection National Association for Music Education, v.36, n.2, p.38-44, 2018.

LIERSE, S. The development of instrumental music programs in Victorian Government secondary schools 1965 to 2000. Doctor of Philosophy (PhD) RMIT University, Melbourne, 2005. https://researchbank.rmit.edu.au/view/rmit:161170

LIERSE, S. The National Review of School Music Education: What is the present state of music education in schools? Australian Association for Research in Music Education. Adelaide, 2006.

MINISTERIAL COUNCIL OF EDUCATION, EMPLOYMENT, TRAINING AND YOUTH AFFAIRS. Melbourne Declaration of Educational Goals for Young Australians. Retrieved from http://www.curriculum.edu.au/verve/_resources/National_Declaration_on_the_ Educational_Goals_for_Young_Australians.pdf, 2008.

MISON, A. 'How can Northern Territory schools implement a quality arts education for every student'. In Northern Territory Department of Education. Queensland Educational Leadership Institute, 2015. 
NORTHERN TERRITORY BOARD OF STUDIES. Policy: Curriculum, Assessment and Reporting Policy: Transition to Year 8. Northern Territory Board of Studies: Darwin, Northern Territory, August 16, 2013.

REEVES, C.; REEVES, P. Designing online and blended learning. In University Teaching in Focus: A learning centred approach. Camberwell, Australia, Australian Council for Educational Research, 2012.

SALAVUO, M. Open and informal online communities as forums of collaborative music activities and learning. British Journal of Music Education, v.23, n.3, p.253-271, 2006.

SMALL, C. Music, education, society. Hanover: Wesleyan University Press, 1977.

VOLK, T. M. Music, education, and multiculturalism: Foundations and principles. New York, NY: Oxford University Press, 2004.

WODAK, R. What CDA is about - a summary of its history, important concepts and its developments. In Wodak, R. and Meyer, M. (Eds). Methods of Critical Discourse Analysis. London: Sage, p.1-13, 2000.

YUNUPINGU, M. Speech to delegates at the Indigenous music education symposium. Northern Territory Music School: Darwin, Northern Territory, 2009. 